\title{
Macrophage expression of active MMP-9 induces acute plaque disruption in apoE-deficient mice
}

\author{
Peter J. Gough, Ivan G. Gomez, Paul T. Wille, and Elaine W. Raines \\ Department of Pathology, University of Washington, Harborview Medical Center, Seattle, Washington, USA.
}

\begin{abstract}
The majority of acute clinical manifestations of atherosclerosis are due to the physical rupture of advanced atherosclerotic plaques. It has been hypothesized that macrophages play a key role in inducing plaque rupture by secreting proteases that destroy the extracellular matrix that provides physical strength to the fibrous cap. Despite reports detailing the expression of multiple proteases by macrophages in rupture-prone regions, there is no direct proof that macrophage-mediated matrix degradation can induce plaque rupture. We aimed to test this hypothesis by retrovirally overexpressing the candidate enzyme MMP-9 in macrophages of advanced atherosclerotic lesions of $a \mathrm{poE}^{-/-}$mice. Despite a greater than 10-fold increase in the expression of MMP-9 by macrophages, there was only a minor increase in the incidence of plaque fissuring. Subsequent analysis revealed that macrophages secrete MMP-9 predominantly as a proform, and this form is unable to degrade the matrix component elastin. Expression of an autoactivating form of MMP-9 in macrophages in vitro greatly enhances elastin degradation and induces significant plaque disruption when overexpressed by macrophages in advanced atherosclerotic lesions of $a \mathrm{poE}^{-/-}$mice in vivo. These data show that enhanced macrophage proteolytic activity can induce acute plaque disruption and highlight MMP-9 as a potential therapeutic target for stabilizing rupture-prone plaques.
\end{abstract}

\section{Introduction}

The past decade has seen a paradigm shift in our understanding of atherosclerosis, and it is now believed that physical rupture of advanced plaques and not lesional stenoses are responsible for the majority of acute clinical manifestations of atherosclerosis, such as myocardial infarction and stroke (1-3). Studies of human atherosclerotic plaques have revealed that lesions that tend to rupture are rich in activated macrophages and have a thin fibrous cap, implicating the macrophage as a key regulator of atherosclerotic plaque stability (4-7). Given that the ECM components collagen and elastin are responsible for the structural integrity of the lesion's fibrous cap, the balance between the synthesis and degradation of these matrix components appears critical for plaque stability. Macrophages are thought to play an important role in this balance due to their ability to produce enzymes capable of degrading the ECM. Members of the MMP and cathepsin families of enzymes appear to have the requisite collagenolytic and elastinolytic activity to destabilize advanced plaques, with several MMPs and cathepsins expressed by macrophages at sites of plaque rupture (8-17). Additional data from human epidemiological and genetic studies suggest that MMP-9 is the strongest candidate for inducing plaque rupture, with its expression correlating strongly to lesion instability and clinical manifestations of atherosclerosis $(8,18-21)$. However, despite all of these supportive data, direct proof for a definitive role of any specific enzyme in ECM degradation and plaque rupture is still lacking.

Nonstandard abbreviations used: EGFP, enhanced green fluorescent protein; G100L, mutation of glycine (residue 100) to leucine in the prodomain of MMP-9; LDLR, LDL receptor; MPO, myeloperoxidase; TIMP, tissue inhibitor of metalloproteinase.

Conflict of interest: The authors have declared that no conflict of interest exists.

Citation for this article: J. Clin. Invest. 116:59-69 (2006).

doi:10.1172/JCI25074.
The absence of suitable animal models has greatly hindered the study of the molecular mechanisms of plaque rupture. Rupture of advanced plaques has recently been reported to occur in the brachiocephalic arteries in apo $E^{-/-}$and $L D L$ receptor-null $\left(L D L R^{-/-}\right)$mouse models of atherosclerosis and appears to mimic many of the characteristics of ruptured human lesions (21-23). However, the incidence of rupture in these mice appears to be too infrequent to practically allow experimental measurements of manipulations that inhibit plaque rupture. The appearance of spontaneous plaque rupture has been accelerated by feeding $a p o E^{-/-}$mice on a mixed genetic background with a diet of $21 \%$ fat from lard supplemented with $0.15 \%$ cholesterol (24-26). Although these perturbations increase the frequency of plaque rupture, highly reproducible plaque rupture is only observed in mice with plasma cholesterol levels greater than $2500 \mathrm{mg} / \mathrm{dl}$. Such high levels of hypercholesterolemia have been shown to alter the immune response $(27,28)$, and thus plaque rupture under this extreme hypercholesterolemia may involve distinct mediators. Although the enhanced incidence of plaque rupture in this model will allow the role of genes to be studied by crossing genedeficient mice onto the apo $E^{-/-}$background, the absence of the gene during all phases of lesion development means it does not represent the ideal experimental approach for specifically defining gene function in advanced lesions and plaque rupture.

We have recently developed a novel macrophage-specific retroviral vector that allows the expression of genes in macrophages in vivo through the transplantation of retrovirally transduced HSCs (29). By expressing apoE in macrophages of apoE $E^{-/-}$mice, we were able to show the utility of this approach for studying gene function during the early phases of atherosclerotic lesion development. In the current study, we have shown that this approach can also be used to examine the function of genes in advanced atherosclerotic lesions by transplanting transduced HSCs into older $a p o E^{-/-}$mice with preestablished lesions. We have used this 

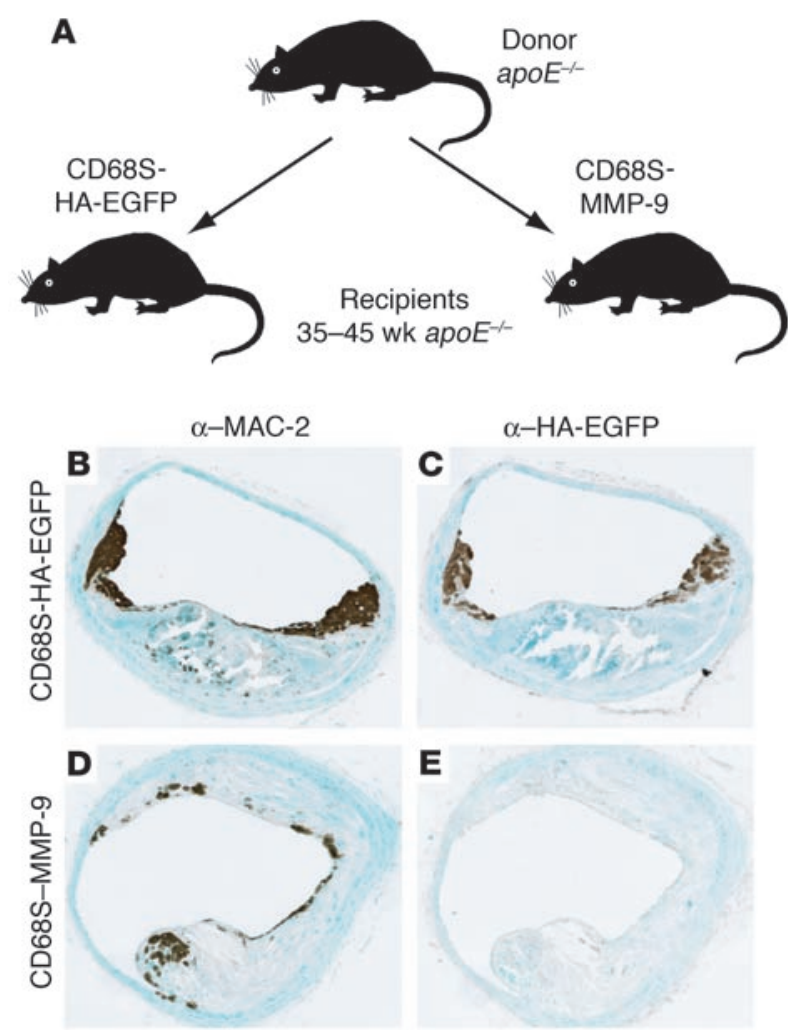

E

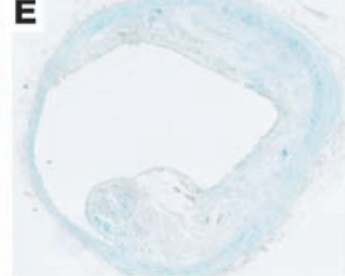

strategy to examine the effects of macrophage overexpression of MMP-9 on the stability of advanced lesions and have shown that an increase in MMP-9 proteolytic activity is sufficient to induce many of the characteristics of plaque rupture. This demonstration that enhanced macrophage proteolytic activity is capable of inducing plaque rupture highlights MMP-9 and factors that regulate its activation as potential therapeutic targets for stabilizing rupture-prone atherosclerotic plaques.

\section{Results}

Retroviral vectors can drive macrophage-specific MMP-9 overexpression in advanced atherosclerotic lesions. To investigate whether the transplantation of retrovirally transduced HSCs could be used to study gene function in advanced atherosclerotic lesions, we first needed to establish that irradiation of older $a p o E^{-/-}$mice did not significantly alter the progression of preestablished lesions. In a pilot experiment, we compared lesions in the brachiocephalic artery and aortic arch between 47- to 57-week-old apoE $E^{-/-}$mice sacrificed 12 weeks after HSC transplant and a control age-matched group that had not been lethally irradiated and did not receive transduced HSCs. Lesion size and morphology were comparable between the 2 groups, indicating that irradiation and transplantation did not significantly alter lesion development (Supplemental Figure 1; supplemental material available online with this article; doi:10.1172/JCI25074DS1), as observed previously in the aortic tree of $L D L R^{-/-}$mice (30).

To explore further the utility of the HSC transplantation approach, we performed the experiment outlined in Figure 1A. Two groups of $10 \mathrm{apoE^{-/- }}$ recipient mice from 35-45 weeks of age were transplanted with HSCs transduced with macrophage-specific retroviral vectors encoding HA epitope-tagged enhanced

\section{Figure 1}

Design and validation of experimental approach. (A) Schematic representation of the HSC transplantation experimental design. Bone marrow cells were harvested from 6- to 8-week-old apoE $E^{--}$donor mice and were transduced with macrophage-specific retroviral vectors encoding HA epitope-tagged EGFP (CD68S-HA-EGFP) or MMP-9 (CD68SMMP-9) (29). After transduction, cells were injected intravenously into 35- to 45-week-old recipient apoE $E^{-/-}$mice. Mice were sacrificed 12 weeks after transplant, and lesion characteristics in the brachiocephalic artery were analyzed. (B-E) Analysis of retroviral gene expression in preestablished atherosclerotic lesions. Immunohistochemistry of similar lesions from $a p o E^{-1-}$ mice transplanted with HSCs transduced with CD68S-HA-EGFP (B and C) or CD68S-MMP-9 (D and E) retroviruses reveals comparable levels of macrophage staining with an antibody recognizing MAC-2 (B and $\mathbf{D})$. Only a subset of macrophages in lesions from mice receiving CD68S-HA-EGFP-transduced HSCs show reactivity with an antibody against the HA epitope (C and $\mathbf{E})$. Original magnification, $\times 10(B-E)$.

green fluorescent protein (EGFP) (CD68S-HA-EGFP) or MMP-9 (CD68S-MMP-9). MMP-9 was chosen as an initial gene of interest due to the large amount of data suggesting that it plays a causative role in plaque rupture $(8,18-21)$.

Relatively little is known about the rate of monocyte recruitment to advanced lesions, and therefore we first wanted to examine whether this HSC transplantation approach could be used to express genes in a significant proportion of macrophages in advanced lesions. Immunohistochemical staining of representative sections of brachiocephalic artery with the macrophagespecific antibody MAC-2 showed similar macrophage content in lesions from both groups of mice (Figure 1, B and D). Sections from mice receiving HSCs transduced with CD68S-HA-EGFP showed the presence of a large number of macrophages expressing HA-EGFP, particularly in the shoulder regions (Figure 1C). Quantification of the MAC-2- and HA-EGFP-positive areas in lesions from all mice transplanted with HSCs transduced with CD68S-HA-EGFP showed that $42.5 \% \pm 6.3 \%$ (mean \pm SEM) of all macrophages expressed HA-EGFP. These data highlight a significant rate of monocyte/macrophage recruitment to advanced lesions and show that the transplantation of retrovirally transduced HSCs can be used to express genes specifically in macrophages in advanced atherosclerotic lesions.

To assess the levels of HA-EGFP and MMP-9 expression generated by the retroviral vectors, we performed immunoblotting and zymography on cell lysates, and supernatants from thioglycollate elicited peritoneal macrophages cultured ex vivo for 24 hours. Expression of HA-EGFP was only seen in macrophages from mice receiving HSCs transduced with CD68S-HA-EGFP (Figure 2A), with $73.5 \% \pm 7.6 \%$ (mean \pm SEM) of cells positive for EGFP (data not shown). The levels of MMP-9 expression generated by CD68SMMP-9 were variable between mice but in all cases were at least 20 -fold greater than the barely detectable levels of MMP-9 produced by the CD68S-HA-EGFP control (Figure 2A).

Given that expression of endogenous MMP-9 can be significantly induced by macrophage activation $(31,32)$, we also examined whether MMP-9 expression was similarly increased by macrophages within atherosclerotic lesions. Immunohistochemical staining revealed low levels of endogenous MMP-9 production by MAC-2-positive macrophages in sections from mice receiving HSCs transduced with CD68S-HA-EGFP (Figure 2, B and C). In contrast, MMP-9 staining intensity was significantly greater in a subset of 
A
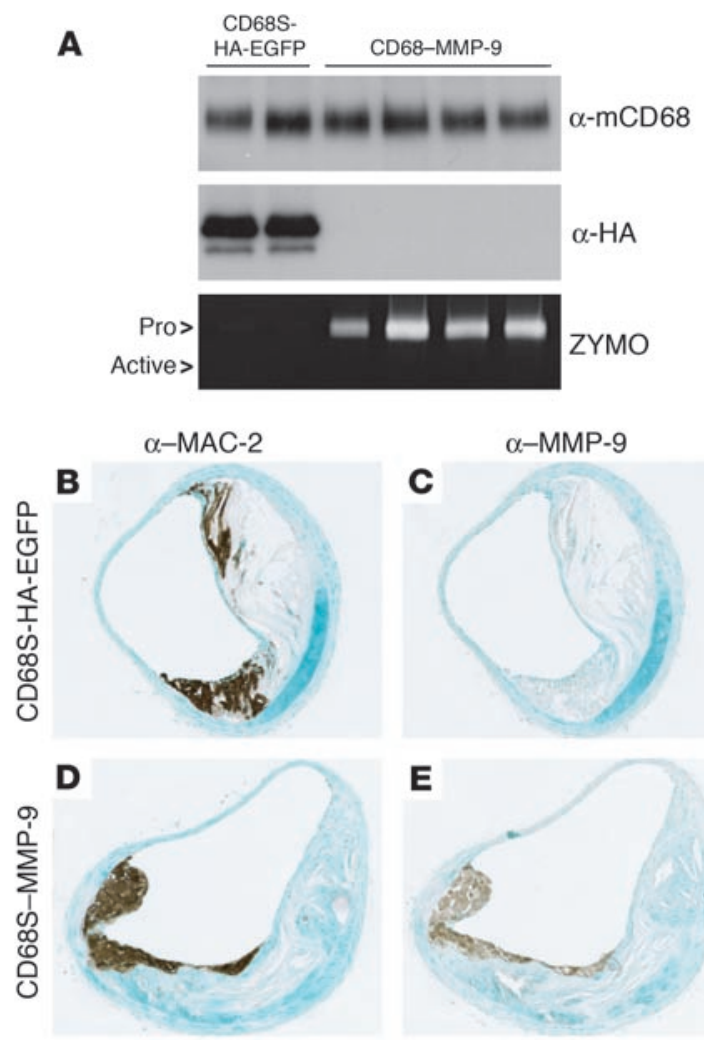
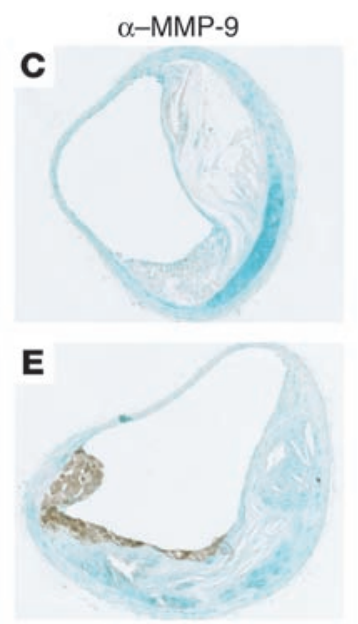

macrophages from the lesions of the CD68S-MMP-9 group (Figures 2, D and E, and 3, E and F), indicating that the expression of MMP-9 was enhanced at least 10 -fold by the retroviral vector.

Macrophage overexpression of MMP-9 does not induce rupture of advanced lesions in apoE $E^{-1-}$ mice. Having established that the transplantation of HSCs transduced with CD68S-MMP-9 led to enhanced macrophage expression of MMP-9, we next examined the functional consequences of this in vivo. Histological examination of a number of macrophage-rich tissues, including spleen, liver, and lung, showed no gross differences between the 2 groups (data not shown), and there were also no alterations in serum cholesterol levels (Table 1). The effect of increased macrophage MMP-9 expression on atherosclerotic lesion integrity was quantified by assessing the presence of disruptions or breaks in the fibrous caps or intraplaque hemorrhage, criteria that have previously been used to measure plaque rupture in the brachiocephalic artery in apo $E^{-/-}$mice $(23,24,26)$. In contrast to previous results, we saw no evidence of plaque rupture in control mice receiving HSCs transduced with CD68S-HA-EGFP, and somewhat surprisingly, there was only 1 animal in the CD68S-MMP-9 group for which evidence of plaque rupture could be seen (Table 1). Similar results were observed in analyses of lesions in the aortic arch (data not shown). These data indicate that macrophage overexpression of MMP-9 is not sufficient to induce robust plaque rupture in $a p o E^{-/-}$mice.

Given the absence of reproducible plaque rupture, we next examined whether MMP-9 overexpression caused any significant changes in the extracellular matrix content of the lesions that may have been insufficient to destabilize the plaque. Analysis of collagen content using Sirius red staining revealed no significant differences in either the fibrous cap or the medial wall between lesions from both groups of mice (Figure 3, C and G). Similarly, Verhoeff-

\section{Figure 2}

CD68S-MMP-9 drives overexpression of MMP-9 in isolated and lesional macrophages. (A) Expression of HA-EGFP and MMP-9 by thioglycollate-elicited macrophages from $a p o E^{-1-}$ mice transplanted with HSCs transduced with either CD68S-HA-EGFP or CD68S-MMP-9 retroviruses was assessed by immunoblotting of lysates $(\alpha-H A)$ or gelatin zymography of supernatants (ZYMO), respectively, from macrophages cultured ex vivo for 24 hours. A similar blot probed with an antibody against macrosialin $(\alpha$-mCD68) served as loading control. Each lane represents samples from macrophages from an individual mouse in each group. Pro, proform. (B-E) Analysis of MMP-9 expression in advanced atherosclerotic lesions. Immunohistochemistry of similar lesions from $a p o E^{-/-}$mice transplanted with HSCs transduced with CD68S-HA-EGFP (B and C) or CD68S-MMP-9 (D and E) retroviruses reveals comparable levels of macrophage staining with an antibody recognizing MAC-2 (B and D). Macrophages in lesions from mice receiving CD68S-MMP-9-transduced HSCs show significantly increased levels of MMP-9 expression compared with lesions from mice receiving CD68S-HA-EGFP-transduced HSCs (C and E). Original magnification, $\times 10$ (B-E).

Van Gieson staining of elastic fibers showed no alterations in the elastin content of the fibrous cap or medial wall nor any changes in the frequency of breaks in the elastic lamellae between the 2 groups (Figure 3, D and $\mathrm{H}$ ).

Activation of MMP-9 is required for elastin degrading capacity in macrophages. The absence of any changes in lesional collagen or elastin content were somewhat unexpected given previous data supporting a role for MMP-9 in matrix remodelling in vivo $(33,34)$. To investigate this further, we examined the in vitro proteolytic activity of macrophages overexpressing MMP-9. The murine macrophage cell line RAW-264.7 was transduced with retroviral vectors encoding MMP-9, MMP-12, or MMP-13, and the elastinolytic capacity of the cells was quantified by measuring the degradation of ${ }^{3} \mathrm{H}$-labeled elastin. Expression of MMP-12 led to a 4-fold increase in elastin degradation, but despite a significant increase in MMP-9 protein expression, the elastinolytic capacity of cells transduced with the MMP-9 encoding vector was the same as in empty vector and MMP-13-transduced controls (Figure 4, A and B).

During our analyses of MMP-9 protein expression by thioglycolate-elicited (Figure 2A) and transduced RAW-264.7 macrophages (Figure 4B) using gelatin zymography, we observed that MMP-9 was exclusively expressed as a $92-\mathrm{kDa}$ proform. Despite previous data showing that this form of MMP-9 can bind and degrade substrates (35), we next investigated whether proteolytic removal of the prodomain of MMP-9 was required for its activity when expressed by macrophages. Mutation of glycine (residue 100) to

\section{Table 1}

Enhanced macrophage expression of MMP-9 does not induce plaque rupture in $a p o E^{-/-}$mice

$\begin{array}{lcc}\begin{array}{l}\text { Age at transplant }(w k) \\ \quad(\text { mean } \pm \text { SEM) }\end{array} & 39.9 \pm 0.9 & 40.7 \pm 0.8 \\ \begin{array}{l}\text { Serum cholesterol }(\mathrm{mg} / \mathrm{dl}) \\ \quad(\text { mean } \pm \text { SEM) }\end{array} & 386 \pm 40 & 373 \pm 56 \\ \text { Fibrous cap disruption } & 0 / 9 & 1 / 9 \\ \text { Intraplaque hemorrhage } & 0 / 9 & 1 / 9 \\ \text { Fibrous cap breaks } & 0 / 9 & 1 / 9\end{array}$



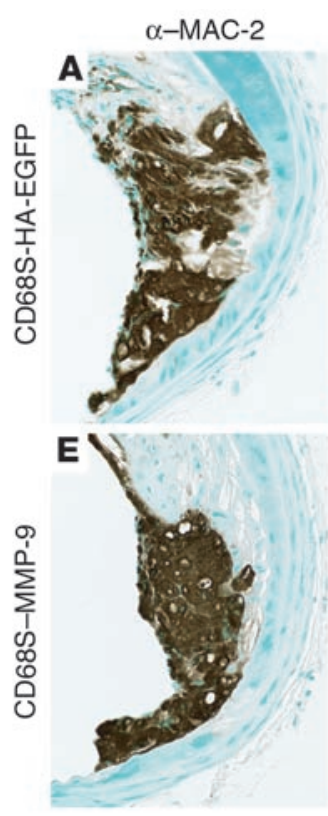

$\alpha-$ MMP-9

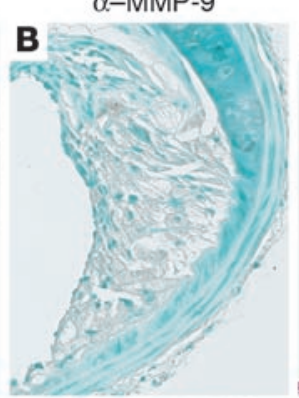

$\mathbf{F}$

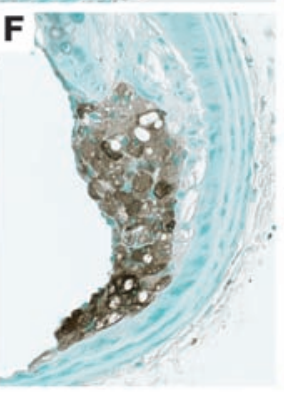

Sirius red

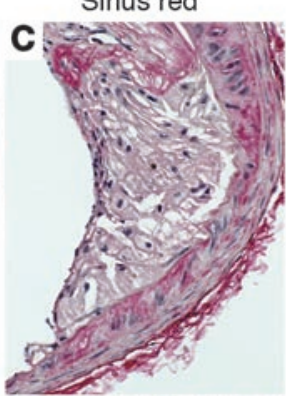

G

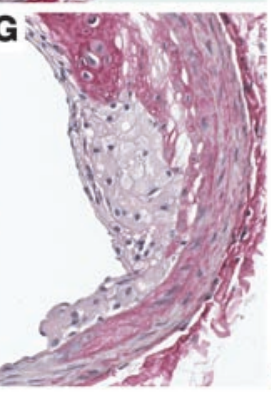

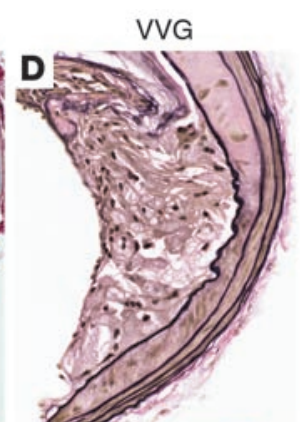

H

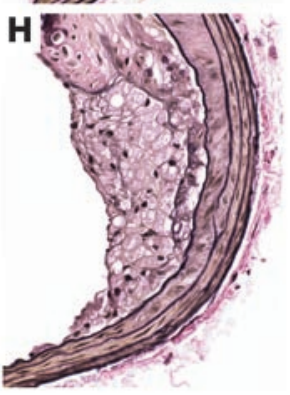

Figure 3

Macrophage overexpression of MMP-9 does not alter lesion matrix composition. Representative shoulder regions from lesions from $a p o E^{-/-}$mice transplanted with HSCs transduced with CD68S-HAEGFP (A-D) or CD68S-MMP-9 (E-H) retroviruses showed similar macrophage content as assessed by staining with an antibody recognizing MAC-2 ( $\mathbf{A}$ and $\mathbf{E}$ ) but significant overexpression of MMP-9 in the group receiving CD68S-MMP-9transduced HSCs (B and $\mathbf{F}$ ). Collagen content, as measured by staining with Sirius red, was similar in lesions from both groups of mice ( $\mathbf{C}$ and $\mathbf{G}$ ), and Verhoeff-Van Gieson (VVG) staining revealed no differences in intimal elastin content or the integrity of the elastin lamelli in the medial arterial wall (D and H). Original magnification, $\times 20(\mathbf{A}-\mathbf{H})$. leucine in the prodomain of MMP-9 (G100L) has previously been shown to weaken the interaction between the prodomain and the catalytic subunit, inducing the autolytic cleavage and removal of the prodomain and the production of active MMP-9 that appears biochemically identical to MMP-9 activated by other means (36). Expression of this mutant in RAW-264.7 cells led to the generation of $82-\mathrm{kDa}$ and $68-\mathrm{kDa}$ processed forms, identical to those seen when native MMP-9 is activated by incubation with 4-aminophenylmercuric acetate (Figure 4B) (37). Elastin degradation by cells expressing MMP-9 G100L was enhanced 4-fold (Figure 4C), indicating that proteolytic processing of MMP-9 is essential for its activity when expressed by macrophages.

Macrophage overexpression of active MMP-9 causes reproducible evidence of plaque rupture in advanced lesions in the brachiocephalic arteries of apoE $E^{-/-}$mice. These findings raised the possibility that the initial in vivo experiment increased levels of MMP-9 protein but not activity expressed by macrophages. To address this, we performed transplants similar to those outlined in Figure 1A but generated 2 groups of apoE $E^{-/-}$mice receiving HSCs transduced with the macrophage-specific vector encoding MMP-9 (CD68SMMP-9) or its autoactivating version (CD68S-MMP-9 G100L). Mice were euthanized 11 weeks after HSC transplant, and levels of MMP-9 expression generated by the 2 constructs were compared by zymography of supernatants from thioglycollate-elicited peritoneal macrophages. Both groups showed similar total levels of MMP-9 protein expression but differed in the form of the enzyme expressed, with the MMP-9 G100L-encoding construct driving the production of MMP-9 in a predominantly active form (Figure 5).

To examine whether these differences in MMP-9 activation status were also seen within atherosclerotic lesions, we performed gela-
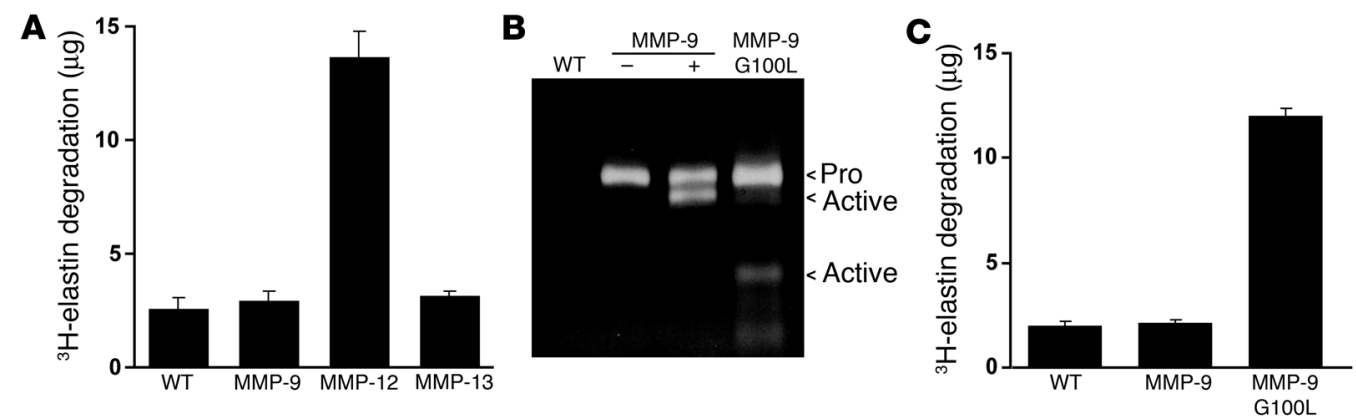

Figure 4

Activation of MMP-9 is required in macrophages for elastin degrading capacity. (A) RAW-264.7 cells transduced with pBM-IRES-PURO retroviral vectors encoding MMP-9, MMP-12, MMP-13, or an empty vector control (WT) were incubated with ${ }^{3} \mathrm{H}$-labeled insoluble elastin for 48 hours. Elastin degradation was quantified by scintillation counting of solubilized ${ }^{3} \mathrm{H}$-elastin in cleared cell supernatants. Bars represent mean $\pm \mathrm{SD}$ from triplicate samples of the quantity of elastin degraded $(\mu \mathrm{g})$ calculated from the specific activity and are representative of triplicate experiments. Only the expression of native MMP-12 induces significant degradation of elastin. (B) Supernatants from RAW-264.7 cells transduced with pBM-IRES-PURO retroviral vectors encoding MMP-9, MMP-9 G100L mutant, or an empty vector control were analyzed by gelatin zymography. Supernatants from cells expressing MMP-9 were incubated in the presence $(+)$ or absence $(-)$ of 4 -aminophenylmercuric acetate to induce activation via the autolytic removal of the prodomain. (C) RAW-264.7 cells described in $\mathbf{B}$ were analyzed for their ability to degrade ${ }^{3} \mathrm{H}$-labeled insoluble elastin as described in $\mathbf{A}$. Representative data from triplicate experiments are represented as in $\mathbf{A}$ and show that expression of the autoactivating G100L MMP-9 mutant significantly enhances elastin degrading capacity. 


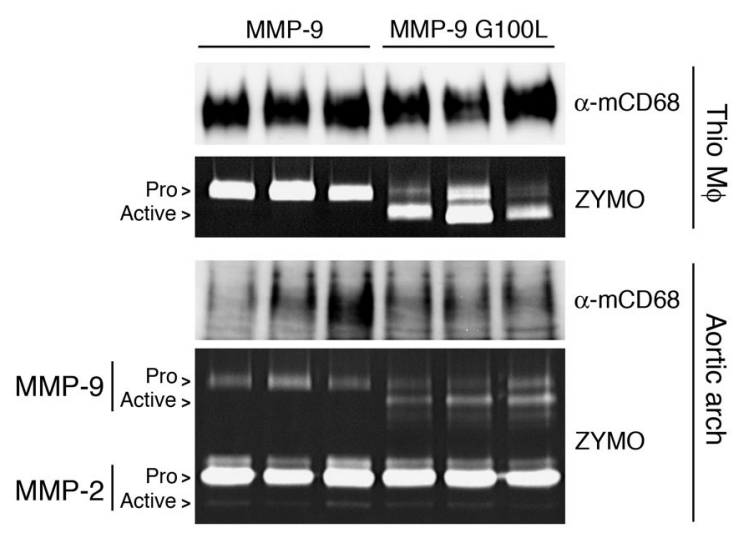

Figure 5

CD68S vectors drive the overexpression of MMP-9 in macrophages and atherosclerotic lesions in apo $E^{-/-}$mice. MMP-9 expression in thioglycollate-elicited peritoneal macrophages (Thio) and aortic arch lysates from apo $E^{-/-}$mice transplanted with HSCs transduced with CD68S-MMP-9 or CD68S-MMP-9 G100L retroviruses was analyzed by gelatin zymography as described in the Figure $2 \mathrm{~A}$ legend. Immunoblotting with an antibody against macrosialin $(\alpha-m C D 68)$ served as loading control for the isolated macrophages and a measure of macrophage content of lesions in the aortic arch. The proforms and active forms of MMP-9 and MMP-2 are highlighted.

tin zymography on samples generated from the aortic arch of the transplanted mice. Lesions from mice receiving HSCs transduced with CD68S-MMP-9 contained MMP-9 exclusively in the proform, indicating the absence of activating stimuli within the lesions (Figure 5). The MMP-9 G100L group showed similar levels of MMP-9 protein expression, but the majority of the enzyme was in the proteolytically activated form. These analyses also revealed comparable levels of MMP-2 protein in the samples from the 2 groups, predominantly in the proform of the enzyme, indicating that an increase in active MMP-9 did not cause a subsequent activation of MMP-2.

During the course of the experiment, 2 mice receiving HSCs transduced with CD68S-MMP-9 G100L died. It was impossible to establish the cause of death in these mice, but the timing of the deaths was inconsistent with any problems with HSC engraftment and repopulation. Comparisons of histology of a panel of organs from the remaining mice from each group failed to show any gross differences to offer potential explanations for these premature deaths (data not shown), and there were also no alterations in serum cholesterol levels (Table 2). Assessment of lesions in the brachiocephalic artery revealed evidence of plaque rupture in 2 of 11 mice in the group receiving HSCs transduced with CD68S-MMP-9 (Table 2), a rate similar to that observed in the initial experiment. In contrast, macrophage expression of autoactivating MMP-9 induced characteristics of rupture of plaques in all mice (10 of 10 ; Table 2 ).

Plaque rupture in these lesions was defined using a number of parameters. A modified version of Carstairs histological stain (38) was used to detect the presence of fibrin deposition within lesions (Figure 6, A-C and $\mathrm{H}$ ), indicative of recent thrombus formation. Fibrin deposits were confirmed by immunohistochemical staining with an anti-fibrin/fibrinogen antibody (Figure 6, D and I), which was controlled for by staining with a nonimmune control IgG (Figure 6E). Lesions from all mice receiving HSCs transduced with CD68S-MMP-9 G100L contained fibrin deposits, and these most often occurred in areas of the plaque underlying a disruption or discontinuity of the elastin layers in the fibrous cap (Figure 6J). In addition to fibrin deposition, virtually all lesions ( 9 of 10; Table 2) containing macrophages expressing autoactivating MMP-9 contained red blood cells (Figure 6, G and H), suggesting hemorrhage into the plaque. A subset of plaques (4 of 10; Table 2) also contained distinct breaks of the fibrous cap in the shoulder region of the lesion (Figure 6J) that were accompanied by significant numbers of red blood cells and fibrin deposition (Figure 6, F-I), indicative of a recent plaque rupture event. Despite rupture of the fibrous cap being apparent in lesions in all mice receiving HSCs transduced with CD68S-MMP-9 G100L, no increase in the frequency of breaks in the elastic lamellae of the medial wall was observed (Figure 6K and Table 2).

In contrast to lesions from mice receiving HSCs transduced with CD68S-MMP-9 G100L, only 2 of 11 lesions containing macrophages expressing native MMP-9 showed evidence of plaque rupture. These ruptured lesions contained fibrin deposits, disrupted fibrous caps and intraplaque hemorrhage, and were indistinguishable from ruptured lesions in the group containing macrophages expressing autoactivating MMP-9. The majority of lesions in mice receiving HSCs transduced with CD68S-MMP-9 (9 of 11; Table 2) were similar to those shown in Figure 6, L-O. There was no evidence of red-orange mature fibrin deposits following Carstairs staining (Figure 6, L and M) although there were areas that showed positive staining with the anti-fibrin/fibrinogen antibody, indicative of the ability of this antibody to recognize multiple forms of this protein (Figure $6 \mathrm{~N}$ ). In addition, elastin staining failed to show any disruptions or breaks in the integrity of the fibrous cap (Figure 6O).

In an attempt to further characterize plaque rupture in lesions containing macrophages expressing autoactivating MMP-9, we measured a number of other lesion parameters (Table 3 ). There was a nonstatistically significant trend for the lesions to be larger in mice receiving HSCs transduced with CD68S-MMP-9 G100L, accompanied by a $29 \%$ decrease in luminal area of the vessel, and a trend toward a larger number of lesional macrophages, although this also did not reach statistical significance. Consistent with the absence of any effect on the integrity of the elastic lamellae in the medial wall, medial and total vessel areas were unchanged between the 2 groups. Despite the increase in plaque rupture in mice transplanted with HSCs transduced with CD68S-MMP-9 G100L, the total amount of collagen in the lesions between the 2 groups was identical.

\section{Table 2}

Enhanced macrophage expression of active MMP-9 induces multiple features of ruptured plaques in the brachiocephalic arteries of $a p o E^{-1-}$ mice

\begin{tabular}{lcc}
\hline & CD68S-MMP-9 & CD68S-MMP-9 G100L \\
Age at transplant (wk) & $41.2 \pm 0.2$ & $41.3 \pm 0.2$ \\
$\quad($ mean \pm SEM) & & \\
$\begin{array}{l}\text { Serum cholesterol (mg/dl) } \\
\quad(m e a n \pm \text { SEM) }\end{array}$ & $475 \pm 48$ & $440 \pm 32$ \\
Premature death & $0 / 11$ & \\
Fibrous cap disruption & $2 / 11$ & $10 / 12$ \\
Intraplaque hemorrhage & $2 / 11$ & $9 / 10$ \\
Fibrin deposition & $2 / 11$ & $10 / 10$ \\
Fibrous cap breaks & $1 / 11$ & $4 / 10$ \\
Medial elastin breaks & $0 / 11$ & $0 / 10$ \\
\hline
\end{tabular}



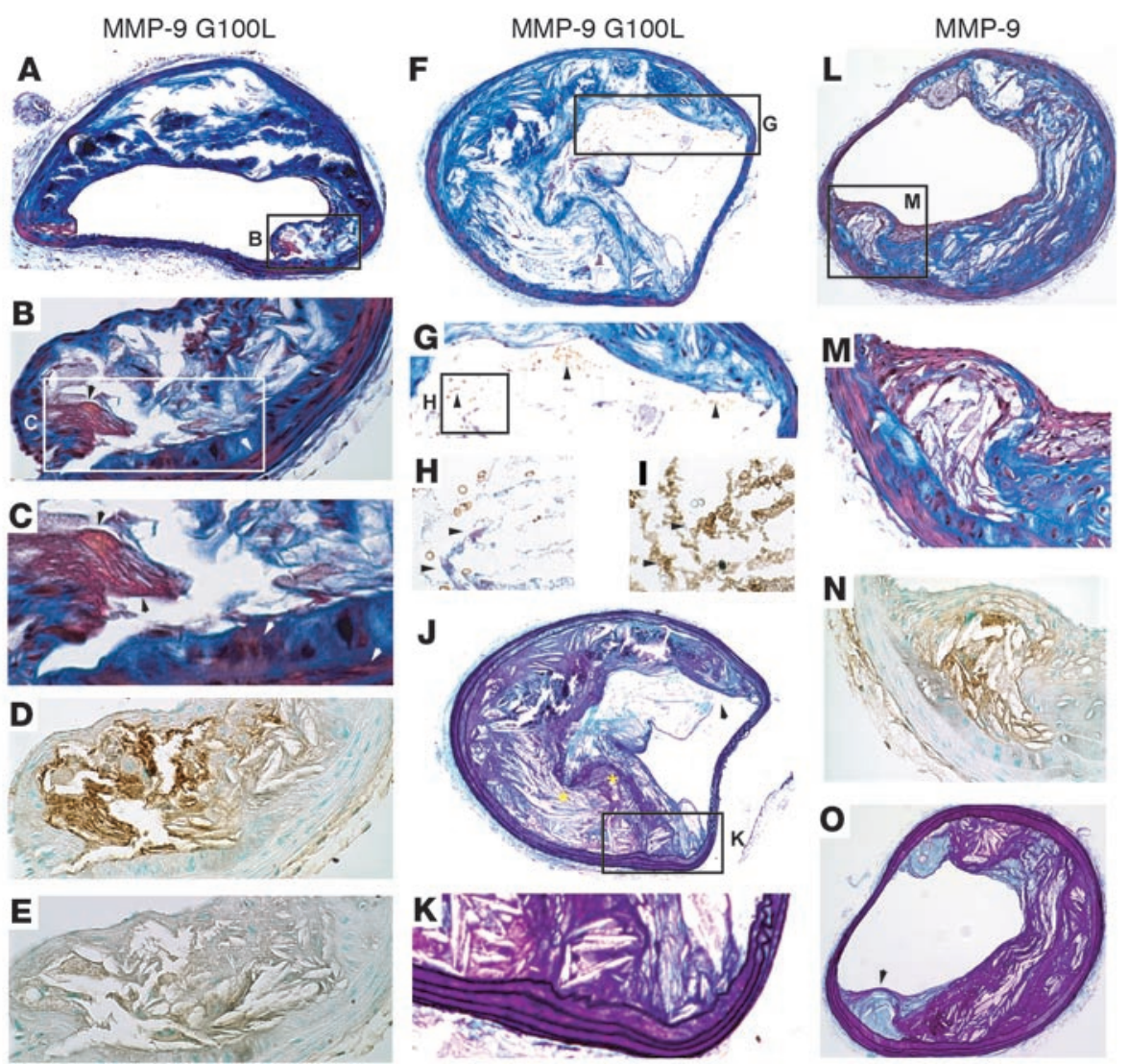

Figure 6

Representative lesions from apoE $E^{-/-}$mice with macrophage overexpression of MMP-9 G100L demonstrate multiple features of ruptured plaques. Representative brachiocephalic lesions from apoE $E^{--}$mice transplanted with HSCs transduced with CD68S-MMP-9 G100L (A-K) or CD68SMMP-9 (L-O) were stained with the following: Carstairs stain $(\mathbf{A}-\mathbf{C}, \mathbf{F}-\mathbf{H}, \mathbf{L}$, and $\mathbf{M})$, Gomori aldehyde fuchsin (GAF) (J, K, and $\mathbf{O})$; a fibrin/fibrinogen antibody (D, I, and $\mathbf{N})$; and control IgG (E). Original magnification, $\times 10(\mathbf{A}, \mathbf{F}, \mathbf{J}, \mathbf{L}$, and O); $\times 20(\mathbf{B}, \mathbf{D}, \mathbf{E}, \mathbf{G}, \mathbf{K}, \mathbf{M}$, and N); $\times 40(\mathbf{C}, \mathbf{H}$, and I). (A-E) The lesion shoulder (A, inset) from a mouse receiving HSCs transduced with CD68SMMP-9 G100L shows fibrin deposition with Carstairs staining (B and C, black arrowheads), distinct from SMCs (B and $\mathbf{C}$, white arrowheads). Fibrin deposition was confirmed by positive staining with anti-fibrin/fibrinogen antibody (D) but not with nonimmune control IgG (E). The staining with the anti-fibrin/fibrinogen antibody was more extensive than Carstairs-positive fibrin areas, but this is consistent with the antibody recognizing multiple forms of the protein (B-D). (F-J) A lesion from a different mouse transplanted with HSCs transduced with CD68S-MMP-9 G100L demonstrates rupture of the thinned fibrous cap (F, inset; $\mathbf{J}$, arrowhead) with rbcs within the lesion (G, arrowheads). It also shows modest Carstairs staining of mature thrombin deposits $(\mathbf{H}$, arrowheads), which were confirmed by fibrin/fibrinogen staining (I, arrowheads). Areas of fibrous cap disruption are apparent with GAF (J, yellow asterisks), but no evidence of elastin destruction in the medial layers is observed $(\mathbf{K})$. (L-O) Lesion from a mouse transplanted with MMP-9-transduced HSCs shows Carstairs staining of SMCs (M, white arrowheads) but no evidence of fibrin deposits, although positive areas are seen with the antibody recognizing fibrin/fibrinogen $(\mathbf{N})$. GAF staining of this lesion ( $\mathbf{O}$ ) shows elastin (arrowhead) covering the shoulder.

dence of rupture. The large size of lesions seen in longitudinal sections of the aortic arch meant that many sites of fibrous cap disruption could be observed within the same plaque (Figure 7A). Ruptures were most commonly seen in the downstream portion of lesions in the lesser curvature (Figure 7B), and these were accompanied by extensive fibrin deposits that often contained numerous red blood cells (Figure 7, $\mathrm{C}-\mathrm{F}$ ). The 2 mice from the group receiving HSCs transduced with CD68S-MMP-9 that showed evidence of plaque rupture had fewer sites of fibrous cap disruption (Figure 7G), but these sites of rupture also exhibited fibrin deposition and intraplaque hemorrhage. These data show that enhanced macrophage expression of active MMP-9 is sufficient to induce the rupture of advanced lesions at multiple sites in the aortic tree of apoE $E^{-/-}$mice and highlight the critical importance of the proteolytic removal of the prodomain for determining the activity of MMP-9 when expressed by macrophages.

\section{Discussion}

The transplantation of bone marrow or transduced HSCs into atherosclerosisprone apoE $E^{-/-}$and $L D L R^{-/-}$mice has been extensively used to dissect the contribution of leukocyte genes to early atherosclerotic lesion initiation and development, but this approach has only recently been applied to study late-stage lesion events exclusively (39). Studies of chemokine receptor-deficient mice have shown that monocyte recruitment is extensive during the initial phases of lesion formation (40-43), but the absence of data on the rate of monocyte influx during the development of advanced lesions has raised questions about the suitability of bone marrow repopulation approaches in examining macrophage function in mature lesions. By transplanting lethally irradiated 35- to 45-week-old apoE $E^{-/-}$mice with HSCs transduced with a macrophage-specific vector encoding HA-epitope tagged EGFP, we were able to show that substantial monocyte recruitment

Macrophage overexpression of active MMP-9 causes reproducible rupture of advanced lesions in the aortic arch of apo $E^{-/-}$mice. To examine whether plaque rupture induced by enhanced macrophage expression of MMP-9 proteolytic activity was confined to lesions in the brachiocephalic artery, we performed similar analyses of lesions in the aortic arch and its branches. All mice receiving HSCs transduced with CD68S-MMP-9 G100L had aortic lesions containing fibrin deposits and fibrous cap disruption (7 of 7; Table 4) while only 2 of 8 aortae from the CD68S-MMP-9 group showed similar evi- still occurs in advanced lesions, with $42 \%$ of macrophages within these lesions ultimately being derived from transduced HSCs during the 12-week period after transplant. As expected, macrophages expressing the HA-EGFP marker were predominantly localized to the shoulder regions of the lesions, mimicking what appears to occur in advanced human lesions. This indicates that transplantation of bone marrow or transduced HSCs into older apoE $E^{-/-}$or $L D L R^{-/-}$mice offers a novel approach for studying gene function in advanced atherosclerotic lesions in isolation and should allow 


\begin{tabular}{|c|c|c|c|}
\hline & $\begin{array}{c}\text { MMP-9 } \\
\text { (mean } \pm \text { SD) }\end{array}$ & $\begin{array}{l}\text { MMP-9 G100L } \\
(\text { mean } \pm \text { SD) }\end{array}$ & $P$ value \\
\hline Lesion area $\left(\mathrm{mm}^{2}\right)$ & $0.204 \pm 0.058$ & $0.224 \pm 0.066$ & 0.079 NS \\
\hline Medial area $\left(\mathrm{mm}^{2}\right)$ & $0.078 \pm 0.012$ & $0.078 \pm 0.020$ & 0.796 NS \\
\hline Lumen area $\left(\mathrm{mm}^{2}\right)$ & $0.128 \pm 0.038$ & $0.091 \pm 0.040$ & $<0.0001$ \\
\hline Vessel area $\left(\mathrm{mm}^{2}\right)$ & $0.407 \pm 0.059$ & $0.393 \pm 0.060$ & 0.204 NS \\
\hline $\begin{array}{l}\text { Lesion collagen, } \\
\text { Sirius red (area \%) }\end{array}$ & $43.67 \pm 8.29$ & $42.4 \pm 8.78$ & $0.293 \mathrm{NS}$ \\
\hline $\begin{array}{l}\text { Lesion macrophages } \\
\text { (area \%) }\end{array}$ & $6.07 \pm 2.46$ & $7.58 \pm 5.56$ & $0.0867 \mathrm{NS}$ \\
\hline
\end{tabular}

comparisons during distinct stages of lesion development. Given the absence of reproducibly quantifiable plaque rupture in mice without induction of extreme hypercholesterolemia, this approach is limited to examining factors that enhance lesion rupture. However, by utilizing measurements of extracellular matrix content and macrophage and smooth muscle cell number, this HSC transplant approach could also be used to investigate the mechanisms that control these determinants of lesion stability.

In our analyses of lesions in $a p o E^{-/-}$mice transplanted with HSCs transduced with CD68S-MMP-9 G100L, we observed many features that have been seen in ruptured human atherosclerotic lesions. We used the presence of a disruption or break in the fibrous cap coupled with fibrin deposition and red blood cells to define the occurrence of plaque rupture. Although the majority of rupture events showed evidence of resolution, lesions were observed where plaque rupture appeared to have occurred very recently. Despite this, we never observed the formation of large occlusive thrombi in the lumen of the brachiocephalic arteries or aortae, as is often seen following rupture of human lesions. The reasons for this are unclear but may represent anatomical differences in the vessel size and physical properties and their associated hemodynamic effects since we analyzed elastic conduit vessels rather than smaller arteries where rupture is most frequently observed. It also may be a reflection of differences in the coagulation and thrombolytic systems between the 2 species. Although our inability to detect luminal thrombus formation means that we do not strictly satisfy the definition of plaque rupture provided by Virmani and colleagues for analyzing human lesions (44), we believe that our observations are sufficient to conclude that we are seeing true plaque rupture of these murine lesions.

We have shown that enhanced macrophage MMP-9 activity is sufficient to induce the rupture of advanced atherosclerotic lesions in $a p o E^{-/-}$mice. These data contrast with a previous study in which the absence of MMP-9 was shown to cause an increase in the incidence of plaque rupture in $a p o E^{-/-}$mice fed a lard-containing, high-fat diet (45). The explanation for these apparently contradictory data on the function of MMP-9 is unclear but may be due to distinct temporal roles for MMP-9 during lesion pathogenesis. In the previous study, the use of MMP-9-deficient mice means that MMP-9 is absent during all stages of lesion development, which contrasts with our overexpression of MMP-9 solely in advanced lesions. Indeed, other studies of early and intermediate lesion formation in $a p o E^{-/-}$mice have shown that the absence of MMP-9 decreases smooth muscle collagen synthesis, a change

that would lead to the development of unstable advanced lesions that were more susceptible to plaque rupture (46). In addition, the apparent discrepancy between these 2 studies may reflect differences in the underlying disease mechanism caused by variations in the extent of hypercholesterolemia, as has been seen previously when examining the role of the immune response $(27,28)$.

Although our results show a potential role for MMP-9 in inducing plaque rupture, utilization of an overexpression approach means that caution is required in extrapolating our data to the normal function of MMP-9 in rupture events. To more fully understand the significance of our data, we are currently performing similar studies with other proteases that have been suggested to induce rupture of lesions. If the ability to initiate plaque rupture is a unique property of MMP-9, then it would add support to the hypothesis that MMP-9-mediated proteolysis is central to the rupture of human lesions. The original rationale for choosing to examine the effect of macrophage MMP-9 overexpression on plaque rupture was based on its ability to degrade elastin and cleaved collagen, abundant components of the extracellular matrix of the fibrous cap of advanced atherosclerotic lesions. Although discontinuities and breaks of elastin were detected in and used to define ruptured caps, we cannot conclude that this was a result of direct MMP-9-mediated cleavage. Several nonmatrix substrates for MMP-9 have been described, and it is possible that MMP-9mediated cleavage of these initiated inflammatory events led to plaque rupture through a distinct mechanism. SCF and IL-8 have both been shown to be substrates for MMP-9, and their cleavage appears to be important in regulating proliferation of bone marrow stem cells and leukocyte recruitment $(47,48)$. Analyses of lesional macrophage content showed that there were no significant differences between groups of mice (Table 3 ), suggesting that enhanced plaque rupture is occurring through a different mechanism. We are currently investigating whether the cleavage of other nonmatrix substrates of MMP-9, including tissue factor pathway inhibitor 1 (TFPI-1) (49), is altered in ruptured lesions and therefore may be able to provide alternate hypotheses of how enhanced MMP-9 activity induces plaque rupture.

The dramatic difference in the incidence of plaque rupture between mice with macrophages overexpressing MMP-9 and those overexpressing autoactivating MMP-9 suggests that the regulation of MMP-9 activity is critical. The activity of MMPs is at least in part controlled by a family of endogenous inhibitors called tissue inhibitors of metalloproteinases (TIMPs). TIMP-1 appears to be most critical for the regulation of MMP-9 activity, and MMP-9 is secreted as a complex with TIMP-1 when expressed by macrophages $(50,51)$. Experiments using TIMPdeficient macrophages have shown that the absence of TIMP-1

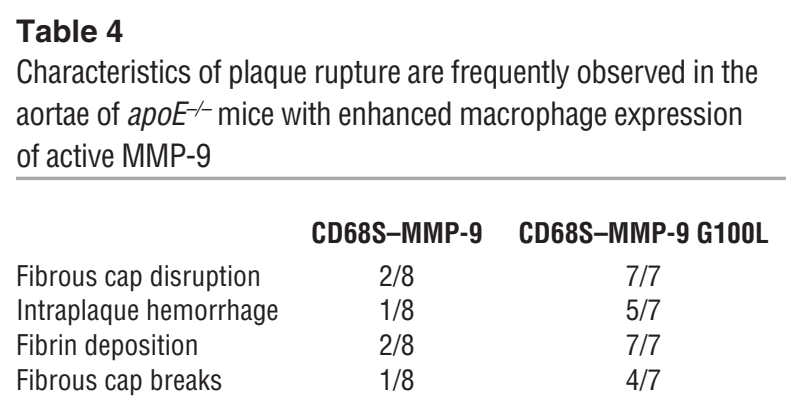

\section{Table 4}

Characteristics of plaque rupture are frequently observed in the aortae of apo $E^{-1}$ mice with enhanced macrophage expression of active MMP-9 

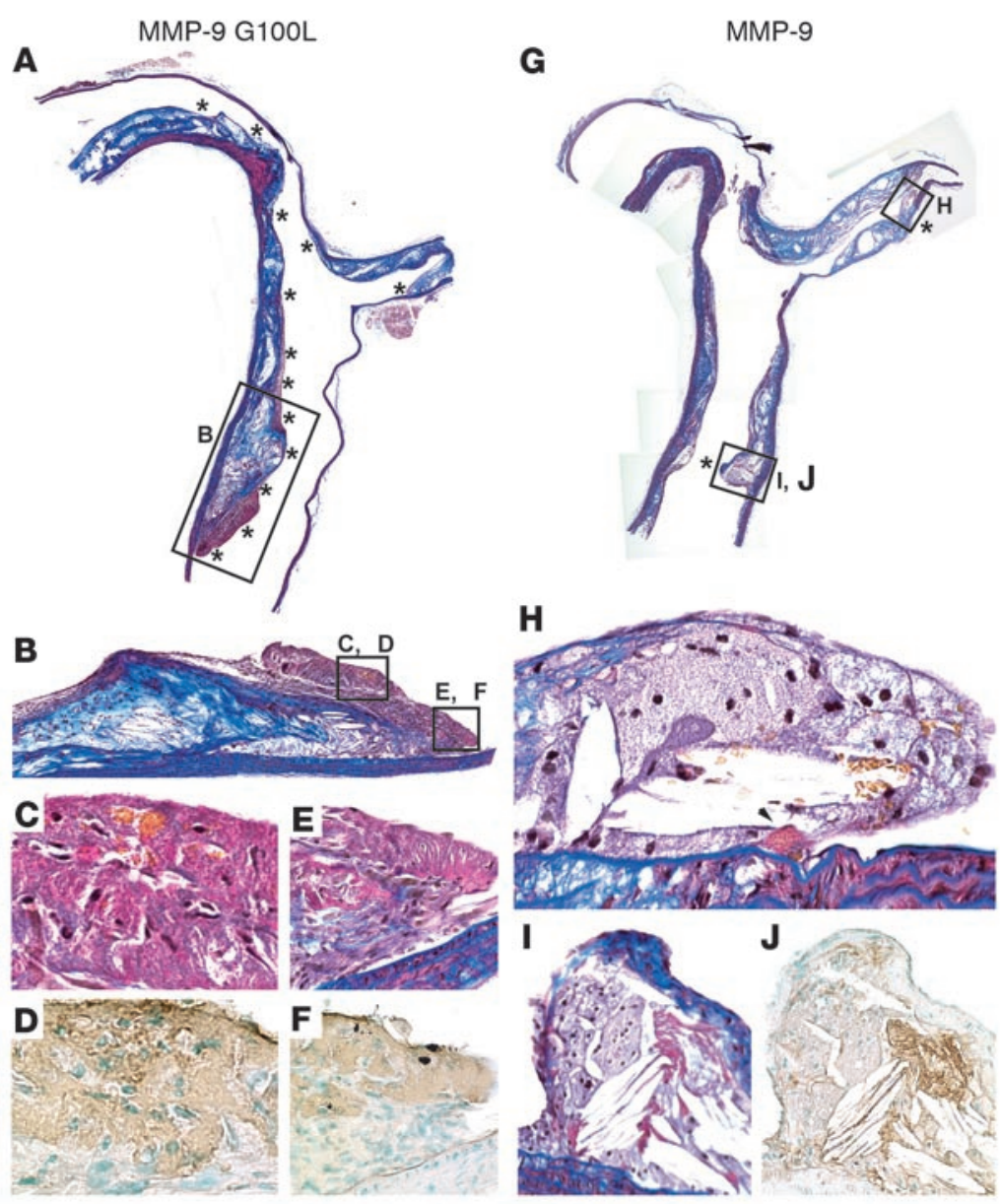

\section{Figure 7}

Multiple sites with characteristics of plaque rupture in the aortae of mice with macrophages expressing MMP-9 G100L. Longitudinal sections of the aortic arch, its branches (minus the brachiocephalic artery), and thoracic aortae stained with Carstairs were evaluated in $a p o E^{-/-}$mice transplanted with HSCs transduced with CD68S-MMP-9 G100L (A-F) or CD68S-MMP-9 (G-J). These lesions represent the most severely affected mice in each group. Original magnification, $\times 10(\mathbf{A}, \mathbf{B}$, and $\mathbf{G}) ; \times 20(\mathbf{H}-\mathbf{J}) ; \times 40$ (C-F). (A-F) A mouse receiving HSCs transduced with CD68S-MMP-9 G100L had at least 13 different regions in which lesions showed evidence of previous plaque rupture (A, asterisks). Rupture was most apparent and frequent at the downstream side of the lesion in the lesser curvature as illustrated at higher magnifications (B-F). rbcs are embedded in a fibrin-rich matrix detected by Carstairs stain (C) and confirmed by anti-fibrin/fibrinogen immunohistochemistry (D), while other areas are primarily fibrin rich (E, Carstairs stain; $F$, fibrin/fibrinogen immunostaining). Features of plaque rupture were observed in all mice in this group $(n=7)$, with at least 5 regions in the lesions in each aorta and its branches. $(\mathbf{G}-\mathbf{J})$ This aorta was from 1 of only 2 of the 8 total mice receiving HSCs transduced with CD68S-MMP-9 that showed any areas with features of plaque rupture in longitudinal sections. The 2 regions boxed in $\mathbf{G}$ with characteristics of plaque rupture are shown at higher power $(\mathbf{H}-\mathbf{J})$. rbcs and a fibrin deposit are seen in $\mathbf{H}$ (black arrowhead), while the lesion in $\mathbf{I}$ and $\mathbf{J}$ shows fibrin deposition by Carstairs (I) that is confirmed by anti-fibrin/fibrinogen staining $(\mathbf{J})$. or TIMP-2 does not enhance the proteolytic autoactivation of MMP-9 (data not shown), suggesting that other mechanisms are involved in regulating macrophage MMP-9 activation in vitro. However, it is likely that the local concentrations of TIMP-1 are important for regulating MMP-9 activity in vivo and may help explain why we did not observe alterations in matrix degradation in other macrophage-rich areas, including the elastic lamellae of the medial arterial wall.

The in vitro experiments using the MMP-9 G100L mutant showed that proteolytic removal of the prodomain is a critical regulator of macrophage MMP-9 activity. Several proteases, including plasmin, trypsin, and MMP-3, have been shown to be capable of similar proteolytic processing of MMP-9 and can act as important determinants of MMP-9 activity in vivo $(37,52-56)$. Given that the activity of many of these proteases is also regulated through proteolytic processing and endogenous inhibitors, it appears that complex regulatory networks exist to ensure the absence of inappropriate proteolytic activity. In addition to activation of MMP-9 by other proteases, autolytic activation of MMP-9 can be induced through chemical modification of a cysteine residue in the prodomain that maintains the enzyme in its inactive state through interactions with the zinc atom in the active site (57-59). Hypochlorous acid and reactive nitrogen species generated by myeloperoxidase (MPO) are both capable of inducing MMP-9 activation, and therefore these activities may offer a potential mechanistic explanation for the correlations between MPO expression and activity and the incidence of myocardial infarction, the clinical consequence of plaque rupture $(60,61)$. It is intriguing that MPO expression is undetectable in murine atherosclerotic lesions and that this correlates with the absence of MMP-9 activation (Figure 5) and plaque rupture (62), and therefore we are currently examining the effect of MPO expression on advanced lesions through the transplantation of retrovirally transduced HSCs.

The data presented in this paper have shown that the transplantation of retrovirally transduced HSCs into older $a p o E^{-/-}$mice is a valuable novel approach for studying gene function specifically in advanced atherosclerotic lesions. Our results lend further support to the hypothesis championed by Libby and colleagues that macrophage-mediated proteolysis is the precipitating event in the rupture of vulnerable plaques and highlight the potential role for MMP-9 in this process. Although further experiments are required to fully understand the true significance of these data, they underline the importance of studying MMP-9 activity rather than just expression when examining its function in vivo. The differences between mice and humans makes the extrapolation of our data difficult; however, these results, coupled with previous epidemiologic and genetic studies $(8,18-21)$, suggest that inhibitors of MMP-9 offer promise as a therapeutic approach for the stabilization of vulnerable plaques. However, given the previous difficulties in generating MMP-specific inhibitors without liabilities that preclude chronic dosing (63), our data suggest that the systems that regulate the proteolytic activation of MMP-9 may represent alternative therapeutic targets. 


\section{Methods}

Retroviral vector generation. All constructs were generated using standard molecular biology techniques and were verified by DNA sequencing. cDNAs encoding murine MMP-9, MMP-12, and MMP-13 were generated by PCR and cloned into the retroviral expression vector PBM-IRES-Puro (64). A single round of PCR-based mutagenesis was used to generate an autoactivating form of MMP-9 by changing G100L as previously described (36). To allow macrophage-specific expression, the MMP-9 cDNA fragments were used to replace HA-EGFP in the vector CD68S-HA-EGFP (29), generating the vectors CD68S-MMP-9 and CD68S-MMP-9 G100L. High-titer retroviral supernatants $\left(>5 \times 10^{6} \mathrm{cfu} / \mathrm{ml}\right)$ were generated by transfection of Phoenix amphotropic and ecotropic packaging cell lines as described previously (29).

Animals. apoE-/- (backcrossed 10 times to C57BL/6J) mice were obtained from the Jackson Laboratory and were maintained under specific pathogen-free conditions and fed a normal chow diet. Thioglycollate-elicited peritoneal cells were generated as previously described (29). All experimental procedures were performed with approval from the Animal Care Committee of the University of Washington.

Bone marrow transduction and transplantation. RAW-264.7 murine macrophages were transduced as described previously (65). For stem cell transplants, bone marrow cells from 5-fluorouracil-treated donors were prestimulated for 48 hours in DMEM containing $15 \%$ fetal calf serum (Invitrogen Corp.), $100 \mathrm{ng} / \mathrm{ml}$ mouse stem-cell factor, $20 \mathrm{ng} / \mathrm{ml}$ human IL-6, and $10 \mathrm{ng} / \mathrm{ml}$ mouse IL-3 (all recombinant and provided by Kirin) prior to two 24-hour periods, in each of which there were 2 hours of centrifugation, using fresh ecotropic retroviral supernatants containing $5 \mu \mathrm{g} / \mathrm{ml}$ polybrene and fibronectin-coated dishes (29). Lethally irradiated (10.5 Gy single dose) recipient apoE $E^{-/-}$mice were injected with $1-2 \times 10^{6}$ infected cells via the lateral tail vein.

Analysis of apoE $E^{-/-}$mice. At 35-45 weeks of age, female apoE $E^{-/-}$mice were transplanted with HSCs transduced with CD68S-based retroviruses encoding either HA-EGFP, MMP-9, or MMP-9 G100L. Mice were injected with thioglycollate 4 days before sacrifice (11 or 12 weeks after transplant), and elicited cells were collected prior to perfusion via the left ventricle with $10 \mathrm{ml}$ PBS containing $1 \mathrm{mM}$ EDTA and $30 \mathrm{ml}$ fixative (PBS, $4 \%$ paraformaldehyde and 5\% sucrose). The heart and aortic tree were dissected and fixed overnight and the brachiocephalic artery and aortic arch were separately embedded in paraffin wax $(66,67)$. For zymographic analyses, the aortic tree was dissected following perfusion with PBS, and the brachiocephalic artery was placed in fixative overnight; the aortic arch was snap-frozen in liquid nitrogen.

For analysis of lesions in the brachiocephalic artery, $1005-\mu \mathrm{m}$ sections were cut and lesion characteristics analyzed every $50 \mu \mathrm{m}$ following either histological or immunochemical staining. In addition to staining with $\mathrm{H} \& \mathrm{E}$ to examine basic lesion morphology, the presence of collagen was assessed by staining with Sirius red, elastin was visualized by either Verhoeff-Van Gieson or Gomori aldehyde fuchsin stain (66), and a modification of Carstairs method to distinguish platelets and fibrin (see Supplemental Methods) was used to detect fibrin (orange-red), red blood cells (yellow), smooth muscle cells (dark red), and collagen (bright blue) (38). Immunohistochemical characterization of the lesions was performed using antibodies recognizing HA-epitope (Zymed Laboratories Inc.), murine MAC-2 (ATCC; monoclonal supernatant diluted 1:4), murine MMP-9 (R\&D Systems), and human fibrin/fibrinogen (DakoCytomation) using a 3-step protocol with $3,3^{\prime}$-diaminobenzidine as chromagen, as described previously (29). For quantitation of lesion parameters, 7 sections (50 $\mu \mathrm{m}$ intervals) per mouse were analyzed using either Image-Pro Plus 4.5 (Media Cybernetics) or ImageJ (NIH; http://rsb.info.nih.gov/ij/) software. The internal and external elastic lamellae and lesion borders were traced and used to derive lumen, lesion, medial, and vessel areas. Macrophage content, HA expression, and collagen content were determined from immunostaining for MAC-2 and HA-epitope and Sirius red histochemical staining, respectively, using color thresholds and are expressed as percentage of lesion area. Other lesion parameters were quantified by 2 independent researchers without knowledge of the tissue source and were defined as follows. An animal was scored positive for fibrous cap disruption when at least 3 sections separated by $50 \mu \mathrm{m}$ showed a discontinuity or disruption in the elastin layer in the cap while a break was defined as a clear break of the fibrous cap into the lumen, often associated with intraplaque hemorrhage, in at least 2 sections separated by $50 \mu \mathrm{m}$ (Figure $6 \mathrm{~J}$ ). Intraplaque hemorrhage was classified as the presence of red blood cells in at least 3 sections separated by $50 \mu \mathrm{m}$ (shown in Figure $6 \mathrm{H}$ ), and medial elastin breaks were scored if there were discontinuities in any of the lamellae of the medial elastin wall. Fibrin deposition was defined as the presence of red-orange Carstairs staining and positive anti-fibrin/fibrinogen immunostaining in serial sections from at least 3 sections of the brachiocephalic artery separated by $50 \mu \mathrm{m}$ (exemplified by Figure 6, B and D).

Quantitation of lesions in the aortic arch was performed using virtually identical criteria to those used for analysis of the brachiocephalic artery, except that analyses were performed on only $1-2$ sections $50 \mu \mathrm{m}$ apart due to the limited number of longitudinal sections that were obtained clearly showing the full length of the aortic arch and its branches and the top portion of the thoracic aorta.

Western blotting and gelatin zymography. Thioglycollate-elicited macrophages, transduced bone marrow-derived macrophages, and RAW-264.7 cells were cultured for 24 hours in serum-free Opti-MEM (Invitrogen Corp.) and lysed in lysis buffer ( $150 \mathrm{mM} \mathrm{NaCl}, 10 \mathrm{mM}$ EDTA, $10 \mathrm{mM}$ $\mathrm{NaN}_{3}, 10 \mathrm{mM}$ Tris ( $\mathrm{pH} 8.0$ ), $2 \mu \mathrm{g} / \mathrm{ml}$ aprotinin, $2 \mu \mathrm{g} / \mathrm{ml}$ leupeptin, $1 \mu \mathrm{g} / \mathrm{ml}$ pepstatin, $100 \mu \mathrm{g} / \mathrm{ml}$ phenylmethylsulphonyl fluoride, and $1 \%$ Nonidet P40). Aortic arch lysates were prepared by pulverizing tissue in lysis buffer using a plastic pestle and a $1.5 \mathrm{ml}$ centrifuge tube. Equal amounts of protein lysate were separated by SDS-PAGE under reducing conditions prior to transfer to Immobilon membrane (Millipore). Membranes were probed with antibodies recognizing the HA-epitope or macrosialin (Serotec) and appropriate peroxidase-conjugated secondary antibodies prior to visualization by ECL (Amersham Pharmacia Biotech). For zymography, conditioned media and aortic arch lysate samples were prepared using nonreducing loading buffer and separated on $7.5 \%$ SDSPAGE gels containing $1 \mathrm{mg} / \mathrm{ml}$ gelatin. After electrophoresis, gels were washed 3 times in wash solution $(150 \mathrm{mM} \mathrm{NaCl}$ and 2.5 Triton $\mathrm{X}-100)$ for 30 minutes, rinsed in water, and incubated for 12-16 hours in digestion buffer $\left(50 \mathrm{mM}\right.$ Tris-Hcl, $\mathrm{pH} 7.5,150 \mathrm{mM} \mathrm{NaCl}, 10 \mathrm{mM} \mathrm{CaCl}_{2}$, and $1 \mu \mathrm{M} \mathrm{ZnCl}_{2}$ ). Gels were subsequently fixed and stained using a Coomassie blue solution as described previously (68).

Quantification of elastin degradation. Bovine ligament elastin (Elastin Products $\mathrm{Co}$.) was radiolabeled with sodium boro $\left[{ }^{3} \mathrm{H}\right]$ hydride as described previously (69), resulting in a specific activity of approximately $1250 \mathrm{cpm} / \mu \mathrm{g}$. RAW-264.7 cells were plated at $5 \times 10^{5}$ cells per well in a 24 -well plate and were cultured for 24 hours prior to the addition of $500 \mu \mathrm{g}{ }^{3} \mathrm{H}$-labeled elastin. After 48 hours incubation, supernatants were harvested and cleared and elastin degradation quantified by scintillation counting. Samples from wells containing elastin without cells were used for background correction, and the specific activity was used to calculate the amount of elastin degraded.

Statistics. Values are expressed as mean \pm SD unless stated otherwise. Data were analyzed using the computer program InStat version 3 (GraphPad Software), and significance was set at $P<0.05$. A check was first made for similarity of variances and normality of distribution, and an unpaired 2 -sample 2-tailed Student's $t$ test was carried out if both passed. If distributions were not normal, a nonparametric Mann-Whitney $U$ test was used, 
and an unpaired 2-sample 2-tailed Student's $t$ test with Welch's correction was applied if variances differed significantly.

\section{Acknowledgments}

We are grateful to Garry Nolan for providing retroviral expression plasmids and to Kirin for providing cytokines. We also thank Karen Honey, Kelli McIntyre, and Paul Martin for help with stem cell transplants; Roderick Browne and Li Huang for expert technical assistance; Carole Wilson and Jingjing Tang for analyzing circulating leukocyte numbers; Dave Madtes for providing TIMPdeficient mice; and Karen Honey, Nicola Ferri, and Kyle Garton for many helpful comments and suggestions. This work was supported by NIH grants HL18645 and HL81795, a postdoctoral fellowship from the American Heart Association, and a University of Washington Royalty Research Award.

1. Libby, P. 2001. Current concepts of the pathogenesis of the acute coronary syndromes. Circulation. 104:365-372.

2. Libby, P., and Aikawa, M. 2002. Stabilization of atherosclerotic plaques: new mechanisms and clinical targets. Nat. Med. 8:1257-1262.

3. Falk, E., Shah, P.K., and Fuster, V. 1995. Coronary plaque disruption. Circulation. 92:657-671.

4. Davies, M.J. 1995. Acute coronary thrombosis-the role of plaque disruption and its initiation and prevention. Eur. Heart J. 16(Suppl. L):3-7.

5. Falk, E. 1992. Why do plaques rupture? Circulation. 86:III30-42.

6. Libby, P. 1998. The interface of atherosclerosis and thrombosis: basic mechanisms. Vasc. Med. 3:225-229.

7. Zhou, J., Chew, M., Ravn, H.B., and Falk, E. 1999. Plaque pathology and coronary thrombosis in the pathogenesis of acute coronary syndromes. Scand. J. Clin. Lab. Invest. Suppl. 230:3-11.

8. Brown, D.L., Hibbs, M.S., Kearney, M., Loushin, C., and Isner, J.M. 1995. Identification of 92-kD gelatinase in human coronary atherosclerotic lesions. Association of active enzyme synthesis with unstable angina. Circulation. 91:2125-2131.

9. Galis, Z.S., Sukhova, G.K., Lark, M.W., and Libby, P. 1994. Increased expression of matrix metalloproteinases and matrix degrading activity in vulnerable regions of human atherosclerotic plaques. J. Clin. Invest. 94:2493-2503.

10. Halpert, I., et al. 1996. Matrilysin is expressed by lipid-laden macrophages at sites of potential rupture in atherosclerotic lesions and localizes to areas of versican deposition, a proteoglycan substrate for the enzyme. Proc. Natl. Acad. Sci. U. S. A. 93:9748-9753.

11. Henney, A.M., et al. 1991. Localization of stromelysin gene expression in atherosclerotic plaques by in situ hybridization. Proc. Natl. Acad. Sci. U. S. A 88:8154-8158.

12. Herman, M.P., et al. 2001. Expression of neutrophil collagenase (matrix metalloproteinase-8) in human atheroma: a novel collagenolytic pathway suggested by transcriptional profiling. Circulation. 104:1899-1904.

13. Li, Z., et al. 1996. Increased expression of 72-kd type IV collagenase (MMP-2) in human aortic atherosclerotic lesions. Am. J. Pathol. 148:121-128.

14. Matsumoto, S., et al. 1998. Expression and localization of matrix metalloproteinase- 12 in the aorta of cholesterol-fed rabbits: relationship to lesion development. Am. J. Pathol. 153:109-119.

15. Nikkari, S.T., et al. 1995. Interstitial collagenase (MMP-1) expression in human carotid atherosclerosis. Circulation. 92:1393-1398.

16. Sukhova, G.K., Shi, G.P., Simon, D.I., Chapman, H.A., and Libby, P. 1998. Expression of the elastolytic cathepsins $\mathrm{S}$ and $\mathrm{K}$ in human atheroma and
Received for publication March 18, 2005, and accepted in revised form October 25, 2005.

Address correspondence to: Peter J. Gough, GlaxoSmithKline, Atherosclerosis Department, Medicines Research Centre, Gunnels Wood Road, Stevenage SG1 2NY, United Kingdom. Phone: 44-1438-764034; Fax: 44-1438-763232; E-mail: peter.j.gough@gsk. com. Or to: Elaine Raines, Department of Pathology, Harborview Medical Center, 325 Ninth Avenue, Box 359675, Seattle, Washington 98104-2499, USA. Phone: (206) 341-5410; Fax: (206) 341-5416; E-mail: ewraines@u.washington.edu.

Peter J. Gough's present address is: GlaxoSmithKline, Atherosclerosis Department, Medicines Research Centre, Stevenage, United Kingdom. regulation of their production in smooth muscle cells. J. Clin. Invest. 102:576-583.

17. Sukhova, G.K., et al. 1999. Evidence for increased collagenolysis by interstitial collagenases- 1 and -3 in vulnerable human atheromatous plaques. Circulation. 99:2503-2509.

18. Blankenberg, S., et al. 2003. Plasma concentrations and genetic variation of matrix metalloproteinase 9 and prognosis of patients with cardiovascular disease. Circulation. 107:1579-1585.

19. Loftus, I.M., et al. 2000. Increased matrix metalloproteinase-9 activity in unstable carotid plaques. A potential role in acute plaque disruption. Stroke. 31:40-47.

20. Pollanen, P.J., et al. 2001. Coronary artery complicated lesion area is related to functional polymorphism of matrix metalloproteinase 9 gene: an autopsy study. Arterioscler. Thromb. Vasc. Biol. 21:1446-1450.

21. Zhang, B., et al. 1999. Functional polymorphism in the regulatory region of gelatinase $B$ gene in relation to severity of coronary atherosclerosis. Circulation. 99:1788-1794.

22. Calara, F., et al. 2001. Spontaneous plaque rupture and secondary thrombosis in apolipoprotein Edeficient and LDL receptor-deficient mice. J. Pathol. 195:257-263.

23. Rosenfeld, M.E., et al. 2000. Advanced atherosclerotic lesions in the innominate artery of the ApoE knockout mouse. Arterioscler. Thromb. Vasc. Biol. 20:2587-2592.

24. Williams, H., Johnson, J.L., Carson, K.G., and Jackson, C.L. 2002. Characteristics of intact and ruptured atherosclerotic plaques in brachiocephalic arteries of apolipoprotein E knockout mice. Arterioscler. Thromb. Vasc. Biol. 22:788-792.

25. Johnson, J., et al. 2005. Plaque rupture after short periods of fat feeding in the apolipoprotein Eknockout mouse: model characterization and effects of pravastatin treatment. Circulation. 111:1422-1430.

26. Johnson, J.L., and Jackson, C.L. 2001. Atherosclerotic plaque rupture in the apolipoprotein $\mathrm{E}$ knockout mouse. Atherosclerosis. 154:399-406.

27. Zhou, X., Paulsson, G., Stemme, S., and Hansson, G.K. 1998. Hypercholesterolemia is associated with a T helper (Th) 1/Th2 switch of the autoimmune response in atherosclerotic apo E-knockout mice. J. Clin. Invest. 101:1717-1725.

28. Robertson, A.K., Zhou, X., Strandvik, B., and Hansson, G.K. 2004. Severe hypercholesterolaemia leads to strong Th2 responses to an exogenous antigen. Scand. J. Immunol. 59:285-293.

29. Gough, P.J., and Raines, E.W. 2003. Gene therapy of apolipoprotein E-deficient mice using a novel macrophage-specific retroviral vector. Blood. 101:485-491.

30. Schiller, N.K., Kubo, N., Boisvert, W.A., and Curtiss,
L.K. 2001. Effect of gamma-irradiation and bone marrow transplantation on atherosclerosis in LDL receptor-deficient mice. Arterioscler. Thromb. Vasc. Biol. 21:1674-1680.

31. Ricote, M., Li, A.C., Willson, T.M., Kelly, C.J., and Glass, C.K. 1998. The peroxisome proliferator-activated receptor-gamma is a negative regulator of macrophage activation. Nature. 391:79-82.

32. Saarialho-Kere, U.K., Welgus, H.G., and Parks, W.C. 1993. Distinct mechanisms regulate interstitial collagenase and $92-\mathrm{kDa}$ gelatinase expression in human monocytic-like cells exposed to bacterial endotoxin. J. Biol. Chem. 268:17354-17361.

33. Longo, G.M., et al. 2002. Matrix metalloproteinases 2 and 9 work in concert to produce aortic aneurysms. J. Clin. Invest. 110:625-632. doi:10.1172/ JCI200215334.

34. Pyo, R., et al. 2000. Targeted gene disruption of matrix metalloproteinase-9 (gelatinase B) suppresses development of experimental abdominal aortic aneurysms. J. Clin. Invest. 105:1641-1649.

35. Bannikov, G.A., Karelina, T.V., Collier, I.E., Marmer, B.L., and Goldberg, G.I. 2002. Substrate binding of gelatinase $\mathrm{B}$ induces its enzymatic activity in the presence of intact propeptide. J. Biol. Chem. 277:16022-16027.

36. Fisher, K.E., et al. 2002. Engineering autoactivating forms of matrix metalloproteinase- 9 and expression of the active enzyme in cultured cells and transgenic mouse brain. Biochemistry. 41:8289-8297.

37. Okada, Y., et al. 1992. Matrix metalloproteinase 9 (92-kDa gelatinase/type IV collagenase) from HT 1080 human fibrosarcoma cells. Purification and activation of the precursor and enzymic properties. J. Biol. Chem. 267:21712-21719.

38. Carstairs, K.C. 1965. The identification of platelets and platelet antigens in histological sections. J. Pathol. Bacteriol. 90:225-231.

39. Guo, J., et al. 2005. Repopulation of apolipoprotein E knockout mice with CCR2-deficient bone marrow progenitor cells does not inhibit ongoing atherosclerotic lesion development. Arterioscler. Thromb. Vasc. Biol. 25:1014-1019.

40. Bursill, C.A., Channon, K.M., and Greaves, D.R. 2004. The role of chemokines in atherosclerosis: recent evidence from experimental models and population genetics. Curr. Opin. Lipidol. 15:145-149.

41. Boring, L., Gosling, J., Cleary, M., and Charo, I.F. 1998. Decreased lesion formation in CCR2-/- mice reveals a role for chemokines in the initiation of atherosclerosis. Nature. 394:894-897.

42. Boisvert, W.A., Santiago, R., Curtiss, L.K., and Terkeltaub, R.A. 1998. A leukocyte homologue of the IL-8 receptor CXCR-2 mediates the accumulation of macrophages in atherosclerotic lesions of LDL receptor-deficient mice. J. Clin. Invest. 101:353-363.

43. Lesnik, P., Haskell, C.A., and Charo, I.F. 2003. Decreased atherosclerosis in CX3CR1-/- mice 
reveals a role for fractalkine in atherogenesis. J. Clin. Invest. 111:333-340. doi:10.1172/JCI200315555.

44. Virmani, R., Kolodgie, F.D., Burke, A.P., Farb, A., and Schwartz, S.M. 2000. Lessons from sudden coronary death: a comprehensive morphological classification scheme for atherosclerotic lesions. Arterioscler. Thromb. Vasc. Biol. 20:1262-1275.

45. Johnson, J.L., George, S.J., Newby, A.C., and Jackson, C.L. 2005. Divergent effects of matrix metalloproteinases $3,7,9$, and 12 on atherosclerotic plaque stability in mouse brachiocephalic arteries. Proc. Natl. Acad. Sci. U. S. A. 102:15575-15580.

46. Luttun, A., et al. 2004. Loss of matrix metalloproteinase- 9 or matrix metalloproteinase- 12 protects apolipoprotein E-deficient mice against atherosclerotic media destruction but differentially affects plaque growth. Circulation. 109:1408-1414.

47. Van den Steen, P.E., Proost, P., Wuyts, A., Van Damme, J., and Opdenakker, G. 2000. Neutrophil gelatinase B potentiates interleukin- 8 tenfold by aminoterminal processing, whereas it degrades CTAP-III, PF-4, and GRO-alpha and leaves RANTES and MCP-2 intact. Blood. 96:2673-2681.

48. Heissig, B., et al. 2002. Recruitment of stem and progenitor cells from the bone marrow niche requires MMP-9 mediated release of kit-ligand. Cell. 109:625-637.

49. Morishige, K., et al. 2003. Overexpression of matrix metalloproteinase- 9 promotes intravascular thrombus formation in porcine coronary arteries in vivo. Cardiovasc. Res. 57:572-585.

50. Welgus, H.G., et al. 1990. Neutral metalloproteinases produced by human mononuclear phagocytes. Enzyme profile, regulation, and expression during cellular development. J. Clin. Invest. 86:1496-1502.

51. Wilhelm, S.M., et al. 1989. SV40-transformed human lung fibroblasts secrete a 92-kDa type IV collagenase which is identical to that secreted by normal human macrophages. J. Biol. Chem. 264:17213-17221.

52. Dreier, R., Grassel, S., Fuchs, S., Schaumburger, J., and Bruckner, P. 2004. Pro-MMP-9 is a specific macrophage product and is activated by osteoarthritic chondrocytes via MMP-3 or a MT1-MMP/ MMP-13 cascade. Exp. Cell Res. 297:303-312.

53. Descamps, F.J., Martens, E., Ballaux, F., Geboes, K., and Opdenakker, G. 2004. In vivo activation of gelatinase B/MMP-9 by trypsin in acute pancreatitis is a permissive factor in streptozotocin-induced diabetes. J. Pathol. 204:555-561.

54. Carmeliet, P., et al. 1997. Urokinase-generated plasmin activates matrix metalloproteinases during aneurysm formation. Nat. Genet. 17:439-444.

55. Heymans, S., et al. 1999. Inhibition of plasminogen activators or matrix metalloproteinases prevents cardiac rupture but impairs therapeutic angiogenesis and causes cardiac failure. Nat. Med. 5:1135-1142.

56. Ramos-DeSimone, N., et al. 1999. Activation of matrix metalloproteinase-9 (MMP-9) via a converging plasmin/stromelysin-1 cascade enhances tumor cell invasion. J. Biol. Chem. 274:13066-13076.

57. Fu, X., Kassim, S.Y., Parks, W.C., and Heinecke, J.W. 2001. Hypochlorous acid oxygenates the cysteine switch domain of pro-matrilysin (MMP-7). A mechanism for matrix metalloproteinase activation and atherosclerotic plaque rupture by myeloperoxidase. J. Biol. Chem. 276:41279-41287.

58. Gu, Z., et al. 2002. S-nitrosylation of matrix metalloproteinases: signaling pathway to neuronal cell death. Science. 297:1186-1190.

59. Rajagopalan, S., Meng, X.P., Ramasamy, S., Harrison, D.G., and Galis, Z.S. 1996. Reactive oxygen species produced by macrophage-derived foam cells regulate the activity of vascular matrix metalloproteinases in vitro. Implications for atherosclerotic plaque stability. J. Clin. Invest. 98:2572-2579.
60. Hazen, S.L. 2004. Myeloperoxidase and plaque vulnerability. Arterioscler. Thromb. Vasc. Biol. 24:1143-1146.

61. Brennan, M.L., and Hazen, S.L. 2003. Emerging role of myeloperoxidase and oxidant stress markers in cardiovascular risk assessment. Curr. Opin. Lipidol. 14:353-359.

62. Brennan, M.L., et al. 2001. Increased atherosclerosis in myeloperoxidase-deficient mice. J. Clin. Invest. 107:419-430.

63. Fingleton, B. 2003. Matrix metalloproteinase inhibitors for cancer therapy:the current situation and future prospects. Expert Opin. Ther. Targets. 7:385-397.

64. Garton, K.J., Ferri, N., and Raines, E.W. 2002. Efficient expression of exogenous genes in primary vascular cells using IRES-based retroviral vectors. Biotechniques. 32:830, 832, 834, passim.

65. Gough, P.J., et al. 2004. A disintegrin and metalloproteinase 10 -mediated cleavage and shedding regulates the cell surface expression of CXC chemokine ligand 16. J. Immunol. 172:3678-3685.

66. Kozaki, K., et al. 2002. Blockade of platelet-derived growth factor or its receptors transiently delays but does not prevent fibrous cap formation in ApoE null mice. Am. J. Pathol. 161:1395-1407.

67. Mach, F., Schonbeck, U., Sukhova, G.K., Atkinson, E., and Libby, P. 1998. Reduction of atherosclerosis in mice by inhibition of CD40 signalling. Nature. 394:200-203.

68. Ferri, N., Garton, K.J., and Raines, E.W. 2003. An NF-kappaB-dependent transcriptional program is required for collagen remodeling by human smooth muscle cells. J. Biol. Chem. 278:19757-19764.

69. Shipley, J.M., Wesselschmidt, R.L., Kobayashi, D.K., Ley, T.J., and Shapiro, S.D. 1996. Metalloelastase is required for macrophage-mediated proteolysis and matrix invasion in mice. Proc. Natl. Acad. Sci. U. S. A. 93:3942-3946. 